Research Article

\title{
Research on the Dynamic Evolution of Scientific and Technological Innovation Efficiency in Universities and Identification of Influencing factors-based on Markov Chain Estimation and GMM Model
}

\author{
Quanzhi Luo iD \\ Sanjiang University, Mechanical and Electrical Engineering College, No. 310, Longxi Road, Yuhuatai District, Nanjing 210012, \\ Jiangsu Province, China \\ Correspondence should be addressed to Quanzhi Luo; sunnynj0108@163.com
}

Received 7 April 2021; Accepted 25 May 2021; Published 8 June 2021

Academic Editor: Muhammet Gul

Copyright (C) 2021 Quanzhi Luo. This is an open access article distributed under the Creative Commons Attribution License, which permits unrestricted use, distribution, and reproduction in any medium, provided the original work is properly cited.

\begin{abstract}
A scientific and comprehensive measurement of the efficiency of scientific and technological innovation activities is the basis and prerequisite for evaluating the existing environment and conditions of universities and is conducive for improving the efficiency and promoting the development of provincial economy. The paper selects the DEA (Data Envelopment Analysis) method to measure the efficiency of scientific and technological innovation in universities of China from 2007 to 2019 and studies its spatial differences. Then, the paper uses Markov chain estimation to describe the dynamic evolution process of the efficiency, and finally uses system GMM (generalized method of moments) model to identify the key influencing factors of its efficiency. The conclusions obtained are as follows: (1) The scientific and technological innovation efficiency in universities presents the highest distribution characteristics in the eastern part, the western part of China has the lowest, and the central part is midway of the two regions. There are significant differences between regions. (2) During the entire observation period, the efficiency in each region showed a path-dependent characteristic. After 2016, the mobility of different levels of technological innovation efficiency of universities in eastern part of China has increased, while in the central and western parts of China it tends to be stable. (3) Economic advantages, location advantages, government support, research and development foundation, and the efficiency of scientific and technological innovation in universities have a significant relationship, and the results are different in different regions.
\end{abstract}

\section{Introduction}

Throughout economic development all over the world, it is not difficult to see that the technological revolution plays an important role in economic growth. Whether or not a country can seize the opportunities brought about by technological innovation will directly affect its future development [1]. Recognizing its important role, countries all over are constantly seeking scientific and technological innovation to improve political and economic development levels. China has also clarified the important position of technological innovation, using technological innovation to drive economic development, and enhancing technological innovation to strengthen its nation. The central role of technological innovation in national development is selfevident, as the country, enterprise, and the people's lives depend on it.

Universities not only cultivate scientific and technological innovation talents but also have obvious advantages in carrying out scientific research work. They shoulder the heavy responsibility of knowledge innovation. Universities have become indispensable in the national innovation system. It is inevitable that there will be resource imbalances between different regions of China. The economic development of each region is different. Therefore, analyzing the scientific and technological innovations of local 
universities, measuring their efficiency is very important. In China, in terms of creating an atmosphere for scientific and technological innovation in universities, government support and enterprise participation have shown an increasing trend [2]. In 2011, the State Council proposed a plan to improve universities' innovation capability; 38 collaborative innovation centers have been established among universities and between colleges and enterprises, aiming to promote and drive the cooperation among universities in the regional innovation system through collaborative innovation centers. In 2015, China stipulated that scientific research institutions and universities established by the state can independently decide on the transfer, license, or price of the scientific and technological achievements held by them. In terms of policy, the state has loosened the transformation of innovation achievements in universities, with the intention to improve the current evaluation system of scientific research institutions and researchers that emphasizes theoretical results and neglects the application of results.

However, we should also be soberly aware that there are still many shortcomings in scientific and technological innovation activities in universities, which need to be improved. Compared with developed countries, Chinese universities are seriously inadequate in investment in technological innovation, infrastructure conditions are relatively backward, and regional distributions vary greatly; the construction of scientific research teams and scientific research management mechanisms are not perfect; and the transformation rate of innovation is low. The application rate of patents granted by Chinese universities is less than $25 \%$. The phenomenon of universities behind closed doors is serious, and the scientific research direction does not match the needs of enterprises [3]. A scientific and comprehensive measurement of the efficiency is the basis and prerequisite for evaluating the existing environment and conditions in universities, and is conducive to improving the efficiency. Studying the promotion or hindrance of the external regional innovation system environment to the technological innovation has certain enlightenment significance for universities and improving its efficiency. In the context of promoting the development of provincial economy, this article analyzes the dynamic evolution of regional universities' science and technology innovation efficiency and explores the impact from the perspective of the province. The key factors can provide a reference for the government to formulate relevant policies.

The main contributions of this paper are (1) selecting super-efficient DEA to measure the efficiency of scientific and technological innovation in Chinese regional universities, and deriving its level for each region; (2) using the Markov chain method to analyze the dynamic changes of each region's efficiency to enable regional universities to understand their changing trends; and (3) using GMM model to verify the factors affecting the efficiency of scientific and technological innovation toward the adoption of differentiated strategies in various regions.

\section{Literature Review}

2.1. Overview of the Evaluation Methods of Scientific and Technological Innovation Efficiency. Judging from the existing domestic and foreign literatures, there are currently two mainstream methods for evaluating the efficiency. One is Data Envelopment Analysis (DEA), which is characterized by not requiring system parameters, and the other is Stochastic Frontier Analysis (SFA), wherein the system needs corresponding parameter settings. Data envelopment analysis (DEA) has been recognized by more scholars. Johnes [4] imported the information of college graduates into the model to measure the efficiency. Flegg et al. [5] broke through the shortcomings of previous scholars using single cross-sectional data. They used multistage data envelopment analysis to evaluate the efficiency in British universities through 12 years of data. Agasisti and Bianco [6] also selected the DEA model to study the innovation efficiency of 58 Italian universities and colleges using two variables: scientific research and teaching. The DEA model has also been widely used in China. Hou and Jin [7] selected the DEA model to measure the efficiency in universities and believed that universities have made considerable progress in innovation capabilities. After this, Hou [8] and Sun et al. [9] also tried to use data envelopment analysis. Shen and Guan [10] measured the innovation efficiency of universities under the national ministry and believed that the innovation efficiency of some universities did not reach the DEA effectively. Shen [11] used the two indicators of income and efficiency as the basis to compare the science and technology of universities in different regions, also using the superefficient DEA model. Li and Zhang [12] used the data envelopment analysis model to measure the innovation ability of universities, and concluded that scale efficiency has the greatest impact on overall efficiency. There are relatively few documents using stochastic frontier analysis methods. Su and Gao [13], Jiang [14], and Yu et al. [15] used interprovincial data and used stochastic frontier functions (SFA) to measure the efficiency, which showed a downward trend. Wang et al. [16] analyzed the dynamic evolution trend of efficiency in Chinese universities using the SFA model, and found that technical efficiency has the characteristics of bipolar clustering, while the provincial difference in scale efficiency is obvious, and the fluctuation characteristics of pure technical efficiency are very obvious. In addition to the above two models, Kao and Hung [17] used multiple linear analysis and clustering methods to measure the innovation efficiency of a university's scientific research department based on the output of publications, the number of patents, and the total teaching hours. Fernando and Cabanda [18] used the method of index analysis for measuring the innovation efficiency.

2.2. Factors Affecting the Efficiency of Scientific and Technological Innovation in Universities. Foreign research on the factors affecting the efficiency of scientific and technological innovation in universities originated from the research of Peters and Etzkowitz [19]. They believed that academic 
research can bring innovation benefits, and this benefit can be transformed into social productivity. As a result, experts and scholars began to explore various reasons that affect innovation efficiency. Through research, it is found that collaboration and cooperation will have a positive relationship between them. Siegel et al. [20] used economic statistical models to compare companies with university science parks nearby in the UK and those without university science parks nearby, and found that companies with university science parks nearby had higher production capacity. Thursby and Thursby [21] believe that the key to improving the efficiency lies in the long-term government investment in scientific research funds. In addition, the economic development is also an important factor. Agrawal et al. [22] found that regions with high economic development levels have strong innovation capabilities.

Domestic research in this area in China started later than foreign countries. Many scholars believe that scientific research funding is an important factor affecting the efficiency. Li and Tian [23] selected 8 years of data from 10 well-known universities in China as a sample. After empirical research, it was found that there is a positive correlation between scientific research funding and patent applications. Yang et al. [24] used the number of patent applications, scientific research funding input, and the number of scientific research personnel in domestic universities in 10 years as indicators to evaluate the relationship between scientific research funding and innovation results. Research results show that the years with more patent applications were inevitably those with large investment in scientific research. Fu et al. [25] found that R\&D input and patent output amount is positively correlated.

\subsection{The Dynamic Evolution of the Efficiency of Scientific and} Technological Innovation in Universities. Li et al. [26] carried out a dynamic analysis of the efficiency of scientific and technological innovation of college teachers to explore the trend of changes in the efficiency of college teachers' technological innovation. Li and Zhang [27] adopted data envelopment analysis CCR model (DEA-CCR) to dynamically inspect scientific research and innovation of universities' performance before and after the implementation of highlevel university construction projects. Chu and $\mathrm{Ma}$ [28] analyzed the third dynamic trend of stage efficiency evolution. Dong and Xing [29] used the nonparametric dynamic DEAMalmquist index method to measure the total factor productivity and decomposition efficiency of scientific and technological innovation in colleges and universities, and used the nonparametric Mann-Whitney method and The Kruskal-Wallis method to examine the difference in efficiency of universities. However, the model only focuses on the change trend of the scientific research efficiency of a single type of decision-making unit but cannot dynamically describe the overall efficiency evolution trend of all decision-making units. Some scholars have used nuclear density to estimate the dynamic evolution trend, such as Wang et al. [16] who analyzed the dynamic evolution trend of the scientific and technological innovation efficiency and the influencing factors. Wang and Jiang [30] analyzed the dynamic evolution process and the change trend of efficiency.

In summary, a lot of research in this area has been done by scholars. In recent years, the temporal and spatial differences and influencing factors have become current academic research hotspots. The latest research has begun to study the dynamic evolution of scientific research efficiency in universities, but the research conclusions need to be expanded. Existing documents have important reference value, but there are still the following shortcomings: (1) Although some scholars analyze the dynamic evolution process of scientific and technological innovation efficiency in universities and add the lack of existing documents, they lack the provincial perspective. The dynamic evolution of innovation efficiency and decomposition indicators is portrayed, so the conclusions still lack universality. (2) Research on efficiency-influencing factors only discusses the impact of external environmental factors in a scattered manner, and lacks a comprehensive systematic analysis of internal and external environments. (3) In terms of sample data, when evaluating efficiency, there are many scholars who use cross-sectional data as sample data. Cross-sectional data cannot show time series changes, and the scientific and technological innovation capabilities of universities are in the process of dynamic development, and their innovation efficiency also has dynamic continuity. Therefore, only using cross-sectional data is one-sided. Based on this, this article intends to use 30 provincial administrative units in China as a sample to measure efficiency, analyze the dynamic evolution process, and examine the changing trend in different regions and find the affecting factors.

\section{Method}

\subsection{Super-Efficiency DEA}

3.1.1. Model Selection. The traditional DEA model was first proposed by Chames et al. with the purpose of analyzing the input and output efficiency of decision-making units under the premise of variable returns to scale. The model under the input orientation is as follows:

$$
\left\{\begin{array}{l}
\operatorname{Min}_{\theta, \lambda}\left[\theta-\varepsilon\left(e^{t} s^{-}+e^{t} s^{+}\right)\right] \\
\text {s.t. } \sum_{i=1}^{n} \lambda_{i} x_{i j}+s^{-}=\theta x_{i j} \\
\sum_{i=1}^{n} \lambda_{i} y_{i r}-s^{+}=\theta y_{i r} \\
\sum_{i=1}^{n} \lambda=1, \quad \lambda_{i} \geq 0, s^{+} \geq 0, s^{-} \geq 0
\end{array}\right.
$$

where $i=1,2, \ldots, n ; j=1,2, \ldots, m ; r=1,2, \ldots, s . n$ is the number of decision-making units, $m$ and $s$ are the number of input variables and output variables. $x_{i j}(j=1,2, \ldots, m)$ is the input element, $y_{i r}(r=1,2, \ldots, s)$ is the output element, $\varepsilon$ is the non-Archimedean infinitesimal quantity, and $s^{+}, s^{-}$are the remaining variables and the slack variable, and $\theta$ 
represents the efficiency value of the decision-making unit (DMU). If $\theta=1$ and $s^{+}=s^{-}=0$, the DEA of the decision unit can be considered valid; if $\theta=1$, and $s^{+}$and $s^{-}$are not all 0 , then the weak DEA of the decision unit is valid; if $\theta<1$, the decision unit is not DEA valid (DEA is invalid).

Andersen and Petersen [31] pointed out the super-efficiency DEA model. The idea is to eliminate the evaluated decision-making units and reconstitute the effective decision-making units of other DEAs into the frontier; when evaluating the decision-making unit, it excludes itself from the reference set of constraints, and then recalculates the decision-making unit, and finally obtains an efficiency value greater than 1. In this way, the efficiency value of the decision-making unit of 1 can be compared. Moreover, since the position of the production frontier has not changed, the efficiency value of the decision-making unit with the previous value less than 1 will not change $[32,33]$.

Since the investigation period of this study is from 2007 to 2019 , spanning 13 years, it is time series data. If the ideal DMU is introduced, the ideal DMU data are composed of the minimum input in earlier years and the maximum output in recent years, which is of little significance in actual production. Therefore, this study selects super-efficient DEA as the evaluation method. The theoretical model is as follows:

$$
\left\{\begin{array}{l}
\operatorname{Min}_{\theta, \lambda}\left[\theta-\varepsilon\left(e^{t} s^{-}+e^{t} s^{+}\right)\right] \\
\sum_{j=1, j \neq j_{0}}^{n} Z_{j} x_{i j}+s_{i}^{-}=\theta_{0} x_{i 0}, i=1,2, \ldots, n \\
\sum_{j=1, j \neq j_{0}}^{n} Z_{j} y_{i r}-s_{j}^{+}=y_{r 0}, r=1,2, \ldots, s \\
Z_{i} \geq 0, j=1,2, \ldots, n, s_{i}^{-} \geq 0, s_{j}^{+} \geq 0 .
\end{array}\right.
$$

Among them, the $j$ th is the super-efficiency value. $\mathrm{Zj}$ reflects the effectiveness of the decision-making unit. $Z_{j}$ may be greater than 1 , and for ineffective units, it is equal to its input-output efficiency. For the effective unit, the larger the $Z_{j}$, the greater the distance between the existing investment level and the new frontier, and the higher the effectiveness of the decision-making unit; it can be sorted by comparing the super-efficiency value of effective decision-making units.

\subsubsection{Selection of Input and Output Indicators and Data} Sources. Innovation activities in institutions of higher learning are complex activities with multiple inputs and multiple outputs. Innovation requires large-scale resource investment, which mainly includes human capital investment and capital investment. The output mainly includes scientific and technological achievements and service output. Indicator system is constructed as shown in Table 1.

(1) Investment Indicators. Research and development (R\&D) full-time personnel are selected as human capital input variables. Labor is a necessary input element in the production process. From the perspective of scientific research, labor input in the scientific research process is the input of scientific research manpower. Since the time and energy invested by researchers in scientific research are different, simply using a number of scientific researchers cannot accurately and truly measure human input. Therefore, this paper chooses the full-time equivalent of research and development personnel as the element of scientific research human input. Full-time personnel refer to researchers who participate in R\&D for more than $90 \%$ of their working hours.

Capital investment selects science and technology expenditures and research and development expenditures as input variables. Another essential input element in the production process is capital investment, and the capital investment in the scientific research process is the scientific research funding investment. The internal expenditure indicators for scientific research in universities reflect the actual expenditures by universities, including scientific research personnel labor costs, scientific research management costs, etc.

(2) Output Indicators. Select the number of published academic papers and the number of published scientific and technological monographs as the output indicators of scientific and technological achievements. Academic papers are the research results of university $R \& D$ personnel in the scientific research process, the most intuitive output of the research and development process, and the most important indicator to measure the scientific research results of universities. Academic papers include three parts: "foreign academic journals," "national academic journals," and "local academic journals." This article uses the sum of the three as output indicators; the number of scientific and technological monographs published can largely reflect the innovation activities of universities to obtain social recognition; the subjects who publish scientific and technological monographs often have high innovation capabilities, so this article also uses this indicator as the output of scientific and technological achievements.

Science and technology services' indicator is the he number of patent applications. This indicator is product of the scientific research and innovation activities of universities, which can reflect the innovation ability of university scientific research.

Each input item and output item in Table 1 must comply with the assumption of "homotropy," that is, when the input quantity is increased, the output quantity cannot be reduced, and the Pearson correlation test method is used to test. Table 2 shows that the correlation coefficients in each region are positive, and both can pass the Pearson correlation test.

The analysis data in this article come from the "China Statistical Yearbook," the "Compilation of Statistics on Science and Technology in Higher Education Institutions." Due to the incomplete scientific research data of universities in Tibet, Hong Kong, Macao, and Taiwan, the sample selected other 30 regions in China and the time span of this 
TABLE 1: Input-output indicator of innovation activities in institutions of higher learning.

\begin{tabular}{|c|c|c|}
\hline Index system & Index type & Index explanation \\
\hline \multirow{3}{*}{ Input index } & Manpower input & $X_{1}$ Research and development of full-time staff (person/year) \\
\hline & 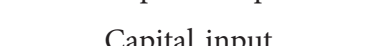 & $X_{2}$ Science and technology investment (thousand yuan) \\
\hline & Capi & $X_{3}$ Research and development funding (thousand yuan) \\
\hline \multirow{3}{*}{ Output index } & Technological achievements & $Y_{1}$ Number of scientific papers (pieces) \\
\hline & lecnnolog & $Y_{2}$ Published scientific and technological works (thousand words) \\
\hline & Technology service & $Y_{3}$ Number of patent applications (items) \\
\hline
\end{tabular}

TABLE 2: Pearson correlation coefficients of variables.

\begin{tabular}{lccc}
\hline Variables & $X_{1}$ & $X_{2}$ & $X_{3}$ \\
\hline$Y_{1}$ & $0.302^{* * *}$ & $0.302^{* * *}$ & $0.282^{* *}$ \\
$Y_{2}$ & $0.112^{* * *}$ & $0.233^{* * *}$ & $0.172^{* * *}$ \\
$Y_{3}$ & $0.173^{* *}$ & $0.282^{* * *}$ & $0.044^{*}$ \\
\hline
\end{tabular}

Note: ${ }^{* * *},{ }^{* *},{ }^{*}$ indicate significance at $1 \%, 5 \%$, and $10 \%$, respectively.

research is 2007-2019. Due to the obvious differences in the level of higher education development, economic development, and financial investment between eastern and central and western parts of China, this article divides the 30 provinces into three major regions: east, central, and west according to the traditional method of dividing economic development levels.

3.2. Markov Chain Method. Russian mathematician Markov, on the basis of Chebyshev's limit theorem, improved the theorem of large numbers and the central limit theorem, and applied them to the study of random variable sequences, and then proposed the Markov process. The article selects the Markov chain method to explore the transfer characteristics of the efficiency in universities from different periods. The basic principle is: the Markov chain is a discrete event stochastic process, that is, $\{X(t), t \in T\}$, set $T$ corresponds to each period. Then for all periods $t$ and all possible states $j, i$, and $i_{k}(k=0,1,2, \ldots, t-2)$, the formulae are $P\left\{X_{t+1}=j \mid X_{0}=i_{0}\right.$, $\left.X_{1}=i_{1}, X_{2}=i_{2}, \ldots, X_{\mathrm{t}}=i\right\}=P\left\{X_{t+1}=\left\{\mid X_{t}=i\right\}\right.$, indicating that the probability is in the state of $j$ depends on the period $t$ status. The transformation of the efficiency from one state to another is called state transition. If each province is divided into $k$ states, then the transition can be expressed by a $k \times k$ transition probability matrix $P$, as shown in equation (3). Based on this, we can explore the dynamic evolution process of universities' efficiency from the perspective of transition probability.

$$
P=\left(\begin{array}{ccc}
P_{11} & \cdots & P_{1 K} \\
\vdots & \ddots & \vdots \\
P_{K 1} & \cdots & P_{K K}
\end{array}\right) .
$$

Among them, $P_{i j}$ represents the one-step transition probability of a province, that is, scientific and technological innovation efficiency level belongs to state $i$ in year $t+1$ to transition to state $j$ in year $t+1 . P_{i j}=n_{i j} / n_{i}, n_{i j}$ represents the sum of the number of provinces in the state $i$ from the th year to the $j$ state in the $t+1$ year, and $n_{\mathrm{i}}$ is in the $j$ state in the $t+1$ years.
3.3. System GMM Model. When the ordinary least squares method is used, the explanatory variable must be uncorrelated with the random error term, otherwise it is a biased estimate; when the instrumental variable method is used, and when it is more than the number of parameters to be estimated, the instrumental variable estimate has a loss of information instead of effective estimation; when using the maximum likelihood method, its parameter estimator is a reliable estimator only when the random error term of the model obeys a normal distribution or a certain known distribution. The GMM calculation method can overcome the problem of random explanatory variables, and can make full use of the information of multiple instrumental variables to overcome the problem of over-identification. At the same time, it does not need to set the random item distribution of the model in advance, so it has become the most common type of model estimation method applied in econometrics application research. Therefore, this paper selects the generalized moment model of the system for regression estimation, and its basic principles are as follows:

Let $y_{i t}=\ln Y_{i t}, x_{i t}=\ln X_{i t}$ level equation is

$$
y_{i t}=\alpha y_{i, t-j}+\beta^{\prime} x_{i t}+\eta_{i}+\mu_{i}+\varepsilon_{i} \text {. }
$$

The first-order difference equation is

$$
\Delta y_{i t}=\alpha \Delta y_{i, t-j}+\beta^{\prime} \Delta x_{i t}+\Delta \mu_{t}+\Delta \varepsilon_{i t} .
$$

The moment condition of the horizontal equation is

$$
\begin{aligned}
E\left[\varepsilon_{i t} \Delta y_{i, t-j}\right] & =0, \quad t=3, \ldots, T, \\
E\left[\varepsilon_{i t} \Delta x_{i t}\right] & =0, \quad t=2, \ldots, T .
\end{aligned}
$$

The first-order difference equation moment conditions are

$$
\begin{aligned}
& E\left[y_{i, t-s} \Delta \varepsilon_{i t}\right]=0, \quad t=3, \ldots, T ; j+1 \leq s \leq t+1, \\
& E\left[x_{i, t-s} \Delta \varepsilon_{i t}\right]=0, \quad t=3, \ldots, T ; 1 \leq s \leq t-1 .
\end{aligned}
$$

Therefore, the tool matrix is composed of the abovementioned moment conditional formula, and the parameter estimator of the dynamic panel model is obtained based on this, which not only solves the endogenous relationship between independent and dependent variables but also avoids synchronization deviation between the independent variables. The systematic GMM method retains the individual differences in the model, and can effectively solve the biased estimation problems that may be caused by weak tools, and is more suitable for analyzing samples with large individual differences such as regions. 


\section{Results}

4.1. The Results of Measuring the Efficiency of Scientific and Technological Innovation. DEAP2.1 software is used to measure the efficiency, as shown in Table 3.

Table 3 reports the time series trend of the scientific and technological innovation efficiency of universities in various regions in China during the observation period. As shown in the table, the efficiency has generally shown an increasing trend during the period from 2007 to 2019. In the process of growth, there have also been fluctuations in efficiency. On a yearly basis, in 2007, the efficiency in China was 0.684 , and in 2008 was 0.750 , which was an increase of 0.066 from 2007, and the growth rate was obvious. In 2009, the efficiency fell back to almost the same as in 2007. In 2009-2011, the efficiency showed a slight increase, from 0.699 in 2009 to 0.804 in 2011, with an average annual increase of 0.035 ; in 2012, the efficiency was 0.732 , which was higher than that in 2011 , reduced by 0.072 ; in 2013 , the efficiency was 0.735 , an increase of 0.003 compared to 2012; in 2015, the efficiency was reduced again, down by 0.049 and reaching 0.690 ; the efficiency begin to increase in 2016; the efficiency increased to 0.746 in 2019 , which is a relatively high position. Generally speaking, the efficiency is relatively stable, and there is no such fluctuation in efficiency as in the first stage.

From the changes of three regions, it shows an overall pattern of "East > Central > West" in the efficiency of scientific and technological innovation in universities. Among them, the eastern and central regions have always been higher than the western region, but in some years, the efficiency of the central region exceeded that of the eastern region. On a yearly basis, during the period 2007-2010, the efficiency in the eastern region was higher than the central region, and the central region was higher than the western region. However, the gap between the three has been narrowing. In 2011, the efficiency of the central region was slightly higher than the eastern region. From 2012 to 2013, the efficiency has restored the basic pattern of "East > Central > West." In 2014, the efficiency in the central region increased significantly, and the efficiency value was 0.01 higher than that of the eastern region. During 2015-2019, the efficiency showed a basic pattern of "East > Central > West." The central region has an efficient downward trend, and western region of China has an efficient growth trend. Compared with the first stage, the fluctuation of efficiency of universities in the east, central, and west of China is relatively stable, and the trend is more obvious. On the one hand, it shows that the overall level of efficiency is not high, and there are regional differences; on the other hand, it also shows that the level of efficiency is not positively related to the development of the economic level. depends on whether the resources are being used rationally.

4.2. Analysis of the Dynamic Evolution of the Efficiency of Scientific and Technological Innovation in Universities. Based on the actual situation of the efficiency in Chinese universities, this article divides the provinces into four states. The standard is: the low-level efficiency of provinces is lower than the national annual average of $75 \%$. Provinces between $75 \%$ and $100 \%$ are called low- to medium-level provinces, those between $100 \%$ and $150 \%$ are called medium- to highlevel provinces, and those higher than $150 \%$ are called highlevel provinces. The previous research results show that 2015 is an important time node for changes in efficiency, so the observation period is divided into two subperiods based on this node. Table 4 shows the Markov chain transfer probability results of universities' scientific and technological innovation efficiency level during the entire observation period and two subperiods.

It can be seen from Table 4 between 2007 and 2019: (1) The transition probability on the diagonal of the country and the three major regions is significantly greater than the transition probability on the off-diagonal line. Taking the whole country as an example, the transition probability on the diagonal is almost all close to 1 , and the minimum value is 0.788 , which is the second element in the second row. That is, nearly $80 \%$ of the low- and medium-level provinces are still at the low-to-medium level at the end of the year. Only $5 \%$ of the provinces shifted downward to a low-level state, and $15 \%$ of the provinces shifted upward to a medium- to high-level state. This shows that the efficiency in each province is greatly restricted by the previous level, showing path-dependent characteristics, resulting in poor liquidity between states. Going deep into the region, the probability that high-level provinces in the eastern region remain stable is 0.952 , and the corresponding probability in the central and western regions is 0 ; the probability that low-level provinces in the eastern region remain stable is 0.887 , and the corresponding probabilities in central and western regions of China are 1 and 0.988 , respectively, resulting in significant gaps between regions. (2) The elements on the off-diagonal lines of the whole country and the three major regions are not all 0 , and they are evenly distributed on both sides of the diagonal line, indicating that the efficiency can be achieved during the two adjacent years of the entire observation period. Transfer between different states. As far as the whole country is concerned, the probability of achieving upward transition is lower than downward transition, and the probability of completing the cross-level transition of efficiency is even slimmer. Meanwhile, the eastern region of China has the highest probability of completing the upward transfer, followed by the western region of China; the central region of China is the weakest.

From the comparison of the two subperiods, 2007-2015 and 2016-2019: (1) In terms of diagonal elements, compared with 2007-2015, 2016-2019 is only the first diagonal element in the country The increase and the decrease in other elements indicate that in 2016-2019, only low-level provinces in the country have self-reinforced, and the mobility of other provinces between different states has increased. At a regional level, the mobility of the eastern region has increased from 2016 to 2019. Similarly, only low-level provinces have seen self-reinforcement, while the central and western regions tend to be more stable. (2) In terms of nondiagonal elements, the arrangement of nondiagonal elements across the country from 2007 to 2015 was relatively scattered, indicating that provinces' efficiencies have cross-level 
TABLE 3: 2007-2019 calculation result.

\begin{tabular}{|c|c|c|c|c|c|c|c|c|c|c|c|c|c|c|c|}
\hline & Region & 2007 & 2008 & 2009 & 2010 & 2011 & 2012 & 2013 & 2014 & 2015 & 2016 & 2017 & 2018 & 2019 & Mean \\
\hline \multirow[t]{11}{*}{ Eastern } & $\lg$ & 34 & 88 & 998 & 54 & 117 & 39 & 142 & 206 & 233 & 248 & 323 & 334 & 168 & .145 \\
\hline & & 852 & 0.995 & .803 & 0.729 & 683 & 0.748 & .758 & 0.516 & & 539 & .537 & 545 & 583 & .677 \\
\hline & & 0.818 & .799 & 0.739 & 0.718 & 0.758 & 0.799 & 0.787 & 0.749 & 0.691 & 0.973 & 0.789 & 0.801 & 0.806 & 0.787 \\
\hline & Liaoning & 0.688 & .894 & 0.772 & 0.788 & 0.897 & 0.762 & 0.926 & 0.869 & 0.832 & 0.787 & .798 & .764 & .773 & .812 \\
\hline & & 1.285 & 1.193 & 0.975 & 0.979 & 0.962 & 0.952 & 0.985 & 0.918 & .871 & 0.832 & .833 & .824 & .913 & .963 \\
\hline & & 0.939 & 1.133 & 0.977 & 0.991 & 1.024 & 1.052 & 1.093 & 1.023 & .035 & 1.119 & 1.161 & .078 & 1.017 & .049 \\
\hline & Zhejiang & 0.816 & 1.023 & 0.981 & 0.983 & 0.949 & 0.932 & 0.905 & 0.878 & 0.868 & 0.889 & 0.905 & .915 & 0.927 & 0.921 \\
\hline & & 0.518 & 0.574 & 0.544 & 0.583 & 0.768 & 0.438 & 0.549 & 0.524 & 0.618 & 0.914 & 0.823 & 0.834 & 0.852 & 0.657 \\
\hline & Shandong & 1.235 & 1.148 & 0.931 & 0.944 & 0.959 & 0.867 & 0.893 & 0.722 & & 0.819 & 733 & .756 & 749 & .874 \\
\hline & Gua & 0.749 & 0.984 & 0.788 & 0.763 & 0.755 & 0.736 & 0.704 & 0.656 & 523 & 0.778 & 89 & .784 & .789 & .754 \\
\hline & & 0.935 & 0.946 & 0.952 & 1.113 & 1.124 & 1.231 & 0.943 & 0.959 & 962 & 0.977 & 0.981 & .997 & .006 & .010 \\
\hline Easter & & 0.888 & 0.971 & 0.860 & 0.877 & 0.909 & 0.878 & 0.880 & 0.820 & 0.805 & 0.898 & 0.870 & 876 & 71 & .877 \\
\hline \multirow[t]{8}{*}{ Central } & Shanxi & 0.736 & 0.848 & 0.851 & 0.986 & 0.852 & 0.861 & 0.896 & 0.817 & & 334 & 83 & 804 & & .843 \\
\hline & & 0.813 & 0.795 & 0.773 & 0.781 & 0.915 & 0.562 & 0.528 & 0.851 & 84 & 788 & 96 & 732 & 746 & .751 \\
\hline & ilongjiang & 0.426 & 0.465 & 0.479 & 0.516 & 0.949 & 0.558 & 0.591 & 0.873 & 0.583 & 0.798 & 0.839 & .785 & 0.701 & .659 \\
\hline & & 0.947 & 0.959 & 0.846 & 0.855 & 0.966 & 0.841 & 0.833 & 0.922 & 0.941 & 0.958 & 0.875 & 895 & 0.902 & 0.903 \\
\hline & & 0.445 & 0.551 & 0.541 & 0.673 & 0.884 & 0.695 & 0.778 & 0.918 & .529 & 0.465 & 476 & 564 & 578 & .623 \\
\hline & & 0.319 & .349 & 0.353 & 0.373 & 0.786 & 0.395 & 0.473 & 0.635 & 0.473 & 0.478 & 0.496 & .502 & 0.521 & .473 \\
\hline & & 0.839 & 0.948 & 0.951 & 1.053 & 1.086 & 0.879 & 0.788 & 0.948 & 0.765 & 0.786 & 0.733 & 679 & 0.688 & 0.857 \\
\hline & & 0.625 & 0.639 & 0.661 & 0.674 & 0.886 & 0.557 & 0.649 & 0.678 & 0.588 & 0.694 & 0.804 & 0.817 & 0.824 & 0.700 \\
\hline Cer & & 0.644 & 0.694 & 0.682 & 0.739 & 0.916 & 0.669 & 0.692 & 0.830 & 0.681 & 0.725 & 0.725 & 0.722 & 0.721 & 0.726 \\
\hline \multirow[t]{11}{*}{ Western } & Neir & 0.592 & 0.499 & 0.485 & 0.561 & 0.536 & 0.528 & 0.739 & 0.654 & 0.676 & 0.682 & 0.711 & .733 & 0.753 & 0.627 \\
\hline & & 0.438 & 0.479 & 0.446 & 0.558 & 0.626 & 0.674 & 0.594 & 0.503 & 0.551 & 0.403 & 0.459 & 0.477 & 0.495 & 0.516 \\
\hline & Chor & 0.549 & 0.853 & 0.762 & 0.849 & 0.986 & 0.939 & 0.987 & 1.041 & 0.933 & 0.969 & 0.728 & 0.798 & 0.811 & 0.862 \\
\hline & & 0.411 & 0.528 & 0.612 & 0.649 & 0.626 & 0.638 & 0.609 & 0.543 & 0.547 & 0.551 & 0.559 & 0.603 & 0.662 & 0.580 \\
\hline & Guizhou & 0.727 & 0.836 & 0.631 & 0.539 & 0.586 & 0.855 & 0.573 & 0.598 & 0.611 & 0.625 & 0.697 & 0.723 & 0.756 & 0.669 \\
\hline & Yunnan & 0.624 & 0.535 & 0.629 & 0.841 & 0.816 & 0.761 & 0.684 & 0.699 & 0.612 & 0.623 & 0.678 & 0.712 & 0.749 & 0.689 \\
\hline & Shaanxi & 0.732 & 0.942 & 0.936 & 0.951 & 0.886 & 0.874 & 0.889 & 0.762 & 0.724 & 0.633 & 0.755 & 0.788 & 0.796 & 0.821 \\
\hline & & & 0.527 & & 0.543 & 0.586 & 0.568 & 0.589 & 0.588 & 0.599 & 0.613 & 0.637 & 0.686 & 0.693 & 0.589 \\
\hline & Qinghai & 0.378 & 0.384 & 0.371 & 0.373 & 0.386 & 0.392 & 0.403 & 0.414 & 0.433 & 0.457 & 0.453 & 0.437 & 0.488 & 0.410 \\
\hline & Ningxia & 0.317 & 0.344 & 0.331 & 0.339 & 0.386 & 0.361 & 0.378 & 0.388 & 0.393 & 0.403 & 0.482 & 0.424 & 0.444 & 0.378 \\
\hline & Xinjiang & 0.334 & 0.343 & 0.332 & 0.352 & 0.386 & 0.375 & 0.389 & 0.303 & 0.325 & 0.339 & 0.449 & 0.354 & 0.372 & 0.350 \\
\hline & & & 0.570 & & 0.596 & 0.619 & 0.633 & 0.621 & 0.590 & 0.582 & 0.573 & 0.601 & 0.612 & 0.638 & 0.590 \\
\hline National mean & & 0.684 & 0.750 & 0.699 & 0.737 & 0.804 & 0.732 & 0.735 & 0.739 & 0.690 & 0.732 & 0.733 & 0.738 & 0.746 & 0.732 \\
\hline
\end{tabular}

TABLE 4: Markov chain transfer probability results.

\begin{tabular}{|c|c|c|c|c|c|c|c|c|c|c|c|c|c|}
\hline \multirow[t]{2}{*}{ Regions } & \multirow[b]{2}{*}{ Standard } & \multicolumn{4}{|c|}{$2007-2019$} & \multicolumn{3}{|c|}{$2007-2015$} & \multicolumn{5}{|c|}{ 2016-2019 } \\
\hline & & Low & $\begin{array}{l}\text { Mid } \\
\text { low }\end{array}$ & $\begin{array}{l}\text { Mid to } \\
\text { high }\end{array}$ & High & Low & $\begin{array}{l}\text { Mid } \\
\text { low }\end{array}$ & $\begin{array}{c}\text { Mid to } \\
\text { high }\end{array}$ & High & Low & $\begin{array}{l}\text { Mid } \\
\text { low }\end{array}$ & $\begin{array}{l}\text { Mid to } \\
\text { high }\end{array}$ & High \\
\hline \multirow{4}{*}{ Whole country } & Low & 0.933 & 0.012 & 0.055 & 0 & 0.943 & 0 & 0.057 & 0 & 0.934 & 0.066 & 0 & 0 \\
\hline & Mid low & 0.049 & 0.788 & 0.163 & 0 & 0 & 0.834 & 0.166 & 0 & 0.134 & 0.745 & 0.121 & 0 \\
\hline & Mid to high & 0.016 & 0.058 & 0.918 & 0.008 & 0.026 & 0.036 & 0.906 & 0.032 & 0 & 0.086 & 0.914 & 0 \\
\hline & High & 0 & 0 & 0.048 & 0.952 & 0 & 0 & 0 & 1 & 0 & 0 & 0.193 & 0.81 \\
\hline \multirow{4}{*}{$\begin{array}{l}\text { Eastern } \\
\text { Region }\end{array}$} & Low & 0.887 & 0.045 & 0.068 & 0 & 0.817 & 0 & 0.183 & 0 & 0.924 & 0.076 & 0 & 0 \\
\hline & Mid low & 0.044 & 0.847 & 0.091 & 0.018 & 0 & 1 & 0 & 0 & 0.082 & 0.727 & 0.191 & \\
\hline & Mid to high & 0 & 0.113 & 0.843 & 0.044 & 0 & 0.056 & 0.903 & 0.041 & 0 & 0.177 & 0.823 & 0 \\
\hline & High & 0 & 0 & 0.048 & 0.952 & 0 & 0 & 1 & 0 & 0 & 0 & 0.188 & 0.91 \\
\hline \multirow{4}{*}{$\begin{array}{l}\text { Central } \\
\text { Region }\end{array}$} & Low & 1 & 0 & 0 & 0 & 1 & 0 & 0 & 0 & 1 & 0 & 0 & 0 \\
\hline & Mid low & 0 & 0.902 & 0.098 & 0 & 0 & 0.818 & 0.182 & 0 & 0 & 1 & & 0 \\
\hline & Mid to high & 0 & 0.021 & 0.979 & 0 & 0 & 0.033 & 0.967 & 0 & 0 & 0 & 1 & 0 \\
\hline & High & 0 & 0 & 0 & 0 & 0 & 0 & 0 & 0 & 0 & 0 & 0 & 0 \\
\hline \multirow{4}{*}{$\begin{array}{l}\text { Western } \\
\text { Region }\end{array}$} & Low & 0.988 & 0 & 0.012 & 0 & 0.971 & 0 & 0.029 & 0 & 1 & 0 & 0 & 0 \\
\hline & Mid low & 0 & 0.551 & 0.449 & 0 & 0 & 0.615 & 0.385 & 0 & 0 & 0.501 & 0.499 & 0 \\
\hline & Mid to high & 0.033 & 0.048 & 0.919 & 0 & 0.035 & 0.048 & 0.917 & 0 & 0.033 & 0.063 & 0.904 & 0 \\
\hline & High & 0 & 0 & 0 & 0 & 0 & 0 & 0 & 0 & 0 & 0 & 0 & 0 \\
\hline
\end{tabular}


transition or decline in the next two years. The elements on the off-diagonal line from 2016 to 2019 are closely arranged on both sides of the diagonal line, indicating that the provinces' efficiency in the adjacent two years can only complete the transfer between neighboring states. Therefore, during 2016-2019, the trend of changes in the efficiency across the country has become more stable. The probability of the eastern region shifting upward and downward in 2016-2019 is not much different, indicating that the level of efficiency in the eastern region has changed drastically at this stage, but the internal gap has changed steadily; the nondiagonal 0 elements in central and western regions are increasingly common, indicating that the mobility of the provinces in the central and western regions is weakened, especially nondiagonal elements in the central region are all 0 , indicating that the path dependence characteristics of the provinces in the central region are the most significant.

\subsection{Analysis of the Impact on the Efficiency of Scientific and Technological Innovation in Universities}

4.3.1. Selection of Indicators for Scientific and Technological Innovation in Universities. A systematic analysis of the environmental factors that affect the efficiency is the key to improve relevant policies, promote the rational allocation of scientific research resources, and enhance the efficiency of universities. The variables in this paper include the following: (1) Economic advantages. The economic level affects the efficiency from two aspects: supply and demand. First, the higher economic level increases government taxation, and government public education funds from taxation account for most of the total education funds, which play a significant role in educational activities. A decisive role and educational activities are the foundation of innovation activities in universities [34]. Secondly, areas with developed high-tech industries often have greater demand for technological innovation in universities and market demand has greatly driven the efficiency [35]. According to the research of Nasierowski and Arcelus [36], this paper selects per capita GDP, per capita value of high-tech industries, and the proportion of tertiary industry added value in GDP as indicators of economic level. (2) Location advantage. Drawing on the research of Frank et al. [37], first introduce the mileage of expressways to reflect the degree of regional traffic convenience; at the same time, dummy variables are introduced to express location differences. (3) The degree of government support. Cao and Li [38], Andrade et al. [39] found that policy support has a significant impact on the innovation efficiency. This paper chooses the proportion of government investment in per capita public education expenditure and $\mathrm{R} \& \mathrm{D}$ expenditure as the indicator of government support. (4) Research and development basis. Most scholars believe that the basic status of $\mathrm{R} \& \mathrm{D}$ is positively related to the efficiency of universities, that is, the better the basic status of R\&D, the greater the effect of scientific research element input on scientific research subjects. Specifically, Li and $\mathrm{Li}[40$ ] pointed out that the R\&D foundation plays a significant positive role in technological innovation through resource allocation effects, knowledge platform effects, human capital effects, and collaborative innovation effects. The paper selects the number of universities, the proportion of PhDs in R\&D personnel, and the proportion of the number of senior professional titles of scientific research personnel in universities as the characterization indicators. The variables are select as follows Table 5 .

4.3.2. Regression Results. This article intends to use the dynamic panel model to measure the various factors affecting the efficiency from a global perspective. In order to avoid the pseudo-regression problem caused by the instability of the data series, it is necessary to conduct a panel unit root test for each variable in turn. Meanwhile, in order to reduce the influence from heteroscedasticity, the variables are logarithmized; there are five main methods for panel unit root test, including LLC test, Breitung test, Hadri test, IPS test, and Fisher test $[41,42]$; the first three are applicable to the same-root situation, and the latter two are applicable to different root situations [2, 43]. In order to ensure the comprehensiveness of the inspection, the article selects the same-root LLC test and different root IPS and Fisher tests to verify and compare the verification results of different methods. Using the above method to carry out unit root test on the data of each research variable, the results are follows Table 6.

In Table 6, the same-root and different root tests have confirmed the stationarity of the variables, and a model can be constructed for further analysis. Therefore, the model is constructed as follows:

$$
\begin{aligned}
Y_{i t}= & \alpha_{0}+\alpha_{1} \mathrm{PGDP}_{i t}+\alpha_{2} \mathrm{PHV}_{i t}+\alpha_{3} \mathrm{THIA}_{i t}+\alpha_{4} \mathrm{LO}_{i t} \\
& +\alpha_{5} \mathrm{HM}_{i t}+\alpha_{6} \mathrm{PE}_{i t}+\alpha_{7} \mathrm{GA}_{i t}+\alpha_{8} \mathrm{UN}_{i t}+\alpha_{9} \mathrm{DN}_{i t}+\mu_{i t} .
\end{aligned}
$$

Among them, each variable is the $i$ th province value in year $t, \beta_{i}$ is the regression coefficient of each variable, $C$ is the individual effect, and $\mu$ is the random error term. Using Stata14.0 software to estimate, the results are shown in Table 7.

According to the regression results: (1) Per capita GDP has a significant negative correlation with the efficiency of universities, indicating that the level of regional macroeconomic development and scientific research and innovation in universities has a restraining effect. The possible reason is that enterprises and scientific research institutions in developed areas have stronger innovation capabilities, which have a "crowding out effect" on the efficiency. The added value of the tertiary industry as a percentage of GDP has a positive contribution to the efficiency of science and technology innovation in universities. For every $1 \%$ increase in the added value, the efficiency will increase by about $5.882 \%$, indicating that regions of high-tech industries have more demand for technological innovation in universities. (2) In terms of location advantages, the efficiency of universities close to the eastern region has increased. This may be mainly related to factors of scientific research foundation 
TABLe 5: Variable selection.

\begin{tabular}{|c|c|c|c|}
\hline $\begin{array}{l}\text { First-level } \\
\text { indicator }\end{array}$ & $\begin{array}{l}\text { Secondary } \\
\text { indicators }\end{array}$ & $\begin{array}{l}\text { Characterization } \\
\text { index }\end{array}$ & Variable code \\
\hline \multirow{10}{*}{$\begin{array}{l}\text { Science and Technology } \\
\text { Innovation } \\
\text { Environment of Universities }\end{array}$} & \multirow{3}{*}{ Economic advantage } & GDP per capita & PGDP \\
\hline & & High-tech industry output value per capita & PHV \\
\hline & & Added value of tertiary industry/GDP & THIA \\
\hline & \multirow{2}{*}{ Location advantage } & Location & LO \\
\hline & & Highway mileage & HM \\
\hline & \multirow[b]{2}{*}{$\begin{array}{c}\text { Government } \\
\text { support }\end{array}$} & Per capita public education expenditure & $\mathrm{PE}$ \\
\hline & & $\begin{array}{c}\text { Government allocated R\&D expenditure/total R\&D } \\
\text { expenditure }\end{array}$ & GA \\
\hline & \multirow{3}{*}{$\mathrm{R} \& \mathrm{D}$ basis } & Number of $\mathrm{PhDs} /$ total number of $\mathrm{R} \& \mathrm{D}$ personnel & $\mathrm{DN}$ \\
\hline & & Number of universities & UN \\
\hline & & Number of senior titles/total number of R\&D personnel & ST \\
\hline
\end{tabular}

TABLE 6: Stationarity test result.

\begin{tabular}{lcccc}
\hline Variable & LLC test & IPS test & Fisher-ADF test & $\begin{array}{c}\text { Fisher-PP } \\
\text { test }\end{array}$ \\
\hline PGDP & $-5.56^{* * *}$ & $-6.19^{* * *}$ & $55.742^{* * *}$ & $103.818^{* * *}$ \\
PHV & $-9.012^{* * *}$ & $-8.021^{* * *}$ & $77.021^{* * *}$ & $132.990^{* * *}$ \\
THIA & $-7.776^{* * *}$ & $-7.376^{* * *}$ & $67.293^{* * *}$ & $117.092^{* * *}$ \\
LO & $-3.768^{* * *}$ & $-4.291^{* * *}$ & $66.872^{* * *}$ & $88.382^{* * *}$ \\
HM & $-4.292^{* * *}$ & $-3.992^{* * *}$ & $55.982^{* * *}$ & $99.012^{* * *}$ \\
PE & $-5.982^{* * *}$ & $-4.129^{* * *}$ & $35.872^{* * *}$ & $98.234^{* * *}$ \\
GA & $-2.992^{* * *}$ & $-7.092^{* * *}$ & $77.092^{* * *}$ & $99.012^{* * *}$ \\
DN & $-6.921^{* * *}$ & $-5.211^{* * *}$ & $55.293^{* * *}$ & $78.120^{* * *}$ \\
UN & $-0.992^{* * *}$ & $-3.827^{* * *}$ & $33.092^{* * *}$ & $69.663^{* * *}$ \\
ST & $-0.882^{* * *}$ & $-4.921^{* * *}$ & $66.921^{* * *}$ & $97.034^{* * *}$ \\
\hline
\end{tabular}

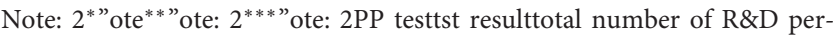
sonnelitureies hi

TABLE 7: Regression results.

\begin{tabular}{lcc}
\hline Factor & Variable & Coefficient of elasticity \\
\hline \multirow{3}{*}{ Economic advantage } & PGDP & $-0.02^{* *}$ \\
& PHV & -0.002 \\
& THIA & $5.882^{* * *}$ \\
\hline \multirow{2}{*}{ Location advantage } & LO & $2.992^{* * *}$ \\
& HM & 0.772 \\
\hline \multirow{2}{*}{ Government support } & PE & $4.134^{* * *}$ \\
& GA & -2.12 \\
\multirow{2}{*}{ R\&D basis } & DN & 0.62 \\
& UN & $0.04^{* * *}$ \\
& ST & -3.09
\end{tabular}

Note: ${ }^{* * *},{ }^{* *},{ }^{*}$ indicate significant at $1 \%, 5 \%$, and $10 \%$, respectively.

and the emphasis on scientific research. It shows that the social environment in the eastern region is more conducive to the optimization of the efficiency, so improving the innovation in central and western regions will narrow the gap between the east and the west to achieve comprehensive and coordinated development. (3) In terms of government policy support, per capita public education expenditure has a greater positive impact on the efficiency, which is the same as previous domestic and foreign research conclusions. At the same time, for every $1 \%$ increase in the natural logarithm of per capita public education expenditure, the efficiency will increase by $4.134 \%$. (4) The condition of infrastructure is positively correlated with the efficiency, that is, the better the condition of R\&D infrastructure, the greater the effect of scientific research element input on scientific research subjects. On the one hand, a good infrastructure condition enhances the capacity to accommodate and train scientific researchers, which is conducive to the conduct of developmental activities in universities. On the other hand, the optimization of the infrastructure level further reduces the cost of the transformation of results and promotes the efficiency. It is further found that the number of universities has a significant positive impact on the efficiency, indicating that improving the capacity of scientific research talents is an important way to optimize the efficiency.

\section{Conclusions and Implication}

5.1. Conclusions. After defining the concept of scientific and technological innovation efficiency in universities, the article uses the DEA method to measure the efficiency and explore the spatial differences of scientific and technological innovation in universities in China from 2007 to 1919. On this basis, it further uses Markov chain estimation to describe the dynamic evolution process of the efficiency. Using the systematic GMM model to identify the key influencing factors of the efficiency, the following main research conclusions are obtained: (1) Firstly, during the sample period, there are obvious differences in efficiency in Chinese universities. Secondly, the lowest distribution characteristics in the western region indicate that the innovation activities of universities form an organic cooperation with the local economic development to a certain extent. The economic development will help the improvement of efficiency. This may be related to the research and development foundation of the region, internal governance structure, high-tech industry development status, achievement transfer platform construction level, and other factors; however, in some years, the central region will be higher than the eastern region of China. The main reason may be due to differences in location, economic level, and knowledge management system. Under the influence of national government policy trends and other factors, the economic development of the western region has a stronger demand for the output of universities' science and technology innovation in the society, which has greatly stimulated the rapid transformation of the social value of science and technology innovation in universities. 
(2) The results of the Markov chain show that the efficiency in each province has a path-dependent characteristic during the entire observation period. After 2016, the mobility of different levels of efficiency in the eastern region has increased, while it is stable in the central and western regions. (3) Through the analysis of the influencing factors, it is found that economic advantages, location advantages, government support, and R\&D foundation have important influences on the efficiency. Therefore, there is a need to vigorously develop strategic emerging industries, improve the state of scientific research and innovation infrastructure in the central and western regions, establish and improve internal governance structures, internal performance evaluation mechanisms, and mechanisms for attracting and training scientific research talents, encouraging the rational flow of high-level scientific research talents, and improving science and technology in universities. Innovation efficiency is of great significance [44].

\subsection{Limitations and Prospects}

(1) The establishment of the input-output indicator system for the innovation efficiency of universities still needs to be improved. First, the indicator construction of the data envelopment analysis method has a certain subjective bias, and the academic fraternity does not have a set of objective and standard indicator selection methods. This subjectivity results in efficiency calculations having certain deviations; Second, part of the input and output indicators cannot be specifically quantified, such as the conversion indicators of scientific research results. Future research needs to find a more comprehensive quantitative treatment method to be more precise. Measure the innovation efficiency of colleges and universities.

(2) Indexes of influencing factors of efficiency need to be enriched. Similar to input-output indicators, the academic circles also have a certain degree of subjectivity in the setting of influencing factor indicators. Any external environment may affect efficiency changes. The paper analyzes the 10 external factors on the innovation efficiency of universities. Follow-up research is needed. Enrich the selection of influencing factors from a more comprehensive perspective.

(3) Spatial spillover effects need to be considered. Because variable influences may have spatial spillover effects, this article does not consider its spatial effects due to space limitations. The author will evaluate the spatial effects in the follow-up research, compare the results obtained with this article, and hope to obtain more valuable results.

\section{Data Availability}

All the data, models, and codes generated or used during the study are included within the submitted article.

\section{Conflicts of Interest}

The authors declare that they have no conflicts of interest.

\section{References}

[1] Y. F. Zhang, "A preliminary study on the role of scientific and technological innovation in social development," Comparative Research on Cultural Innovation, vol. 4, pp. 36-37, 2020.

[2] Q. Gao, F. He, and Q. Lu, "Research on the efficiency of universities science and technology innovation under the background of industry-universities-research collaborative innovation-an empirical analysis based on panel data of key universities in China," Research and Development Management, vol. 32, no. 5, pp. 179-190, 2020.

[3] L. Zeng and X. Liu, "Review and prospects of universities patent transformation research based on industry-universities-research collaborative innovation," Innovation Science and Technology, vol. 20, no. 248, pp. 71-78, 2020.

[4] J. Johnes, "Measuring efficiency: a comparison of multilevel modelling and data envelopment analysis in the context of higher education," Bulletin of Economic Research, vol. 2, pp. 75-104, 2010.

[5] A. T. Flegg, D. O. Allen, and K. Field, "Measuring the efficiency of British universities: a multi-eriod data envelopment analysis," Education Economics, vol. 3, pp. 231-249, 2004.

[6] T. Agasisti and A. D. Bianco, "Reforming the universities sector: effects on teaching efficiency-evidence from Italy," Higher Education, vol. 57, no. 4, pp. 477-498, 2009.

[7] G. M. Hou and L. L. Jin, "Application of DEA method in performance evaluation of research universities construction," Development of Higher Education and Evaluation, vol. 21, no. 5, pp. 25-29, 2005.

[8] Q. P. Hou, "Research on the application of DEA-based scientific research performance evaluation in research universities," Research and Development Management, vol. 17, no. 1, pp. 118-124, 2005.

[9] S. M. Sun, H. L. Xiang, and B. Lan, "DEA-based analysis of input and output efficiency of scientific research in Chinese regional universities," Section Learning and Management of Science and Technology, vol. 28, no. 7, pp. 18-21, 2007.

[10] Y. C. Shen and C. Guan, "Research on the efficiency of national defense science and technology innovation based on DEA," Beijing Airlines Journal of Universities of Astronautics (Social Science Edition), vol. 23, no. 5, pp. 108-111, 2010.

[11] N. Shen, "The measurement of universities knowledge innovation efficiency and spatial convergence analysis," Science of Science and Management of Science and Technology, vol. 33, no. 5, pp. 84-89, 2012.

[12] S. P. Li and X. M. Zhang, "Evaluation of the science and technology innovation ability of universities in henan province-based on data envelopment analysis," Zhongyuan Journal of Engineering College, vol. 26, no. 2, pp. 86-89, 2015.

[13] T. Y. Su and Q. Gao, "Research on the efficiency and difference of universities science and technology innovation based on stochastic frontier analysis," Forecast, vol. 6, pp. 61-65, 2012.

[14] T. T. Jiang, "Research on the measurement and evaluation of universities R\&D innovation efficiency," China Science and Technology Resources Guide, vol. 44, no. 3, pp. 61-66, 2012.

[15] Z. J. Yu, C. H. Yang, Y. Bai Yu, and Z. L. Peng, "Research on the efficiency and influencing factors of universities science and technology innovation from the perspective of 
achievement types," Research Management, vol. 38, no. 5, pp. 141-149, 2017.

[16] X. Z. Wang, Z. H. Jiang, and Y. Zheng, "Dynamic evolution analysis and influencing factors identification of scientific and technological innovation efficiency in universities-based on non-Parameter kernel density estimation and SFA model," Statistics and Information Forum, vol. 33, no. 9, pp. 81-87, 2018.

[17] C. Kao and H. T. Hung, "Efficiency analysis of universities departments: an empirical study," Omega, vol. 36, no. 4, pp. 653-664, 2008.

[18] B. I. S. Fernando and E. C. Cabanda, "Measuring efficiency and productive performance of colleges at the universities of Santo Tomas: a nonparametric approach," International Transactions in Operational Research, vol. 14, no. 3, pp. 217-229, 2010.

[19] L. S. Peters and H. Etzkowitz, "Universities-industry connections and academicvalues," Technology in Society, vol. 12, no. 4, pp. 427-440, 1990.

[20] D. S. Siegel, P. Westhead, and M. Wright, "Assessing the impact of universities science parks on research productivity: exploratory firm-level evidence from the United Kingdom," International Journal of Industrial Organization, vol. 21, no. 9, pp. 1357-1369, 2003.

[21] J. G. Thursby and M. C. Thursby, "Who is selling the ivory tower? Sources of growth in universities licensing," Management Science, vol. 48, no. 1, pp. 90-104, 2002.

[22] A. Agrawal, I. M. Cockburn, and J. Mchale, "Gone but not forgotten: labor flows, knowledge spillovers, and enduring social capital," Social Science Electronic Publishing, vol. 49, no. 4, pp. 1251-1295, 2003.

[23] Y. Q. Li and S. Y. Tian, "The status quo, constraints and countermeasures of the transformation of scientific and technological achievements in Chinese universities," Higher Agricultural Education, vol. 2, pp. 37-39, 2005.

[24] J. Yang, Y. B. Lv, and Z. L. Liu, "Research on the correlation model of universities science and technology input and output," Inner Mongolia Science and Technology and Economy, vol. 27, no. 2, pp. 78-82, 2005.

[25] Y. Fu, L. P. Zhang, and Q. Ma, "The impact of R\&D resource input on patent output of different types of universities," Research and Development Exhibition Management, vol. 22, no. 3, pp. 103-111, 2010.

[26] Q. X. Li, S. W. Qu, and S. Y. Qi, "Research on the efficiency of science and technology innovation of universities directly under the Ministry of Education-based on the dynamic analysis of the Malmquist index method from 2007 to 2011," Research in Higher Education of Engineering, vol. 3, pp. 167-171, 2014.

[27] Y. T. Li and R. X. Zhang, "Dynamic evaluation of the efficiency of scientific research and innovation in Guangdong universities-a comparative analysis before and after the construction of high-level universities," Science and Technology Management Research, vol. 40, no. 4, pp. 127-133, 2020.

[28] X. X. Chu and Y. Ma, "Evaluation of the efficiency of science and technology innovation in Chinese universities from the perspective of innovation value chain," Science and Technology Management Research, vol. 40, no. 22, pp. 126-130, 2020.

[29] X. F. Dong and L. P. Xing, "Nonparametric statistical research on the efficiency of science and technology innovation in universities directly under the Ministry of Education," Statistics and Management, vol. 35, no. 4, pp. 22-26, 2020.
[30] X. Z. Wang and Z. H. Jiang, "Analysis of the efficiency and environment of scientific and technological innovation in Chinese universities: a perspective of value types," Scientific Research Management, vol. 40, no. 10, pp. 28-39, 2019.

[31] P. Andersen and N. C. Petersen, "A procedure for ranking efficient units in data envelopment analysis," Management Ence, vol. 39, no. 10, pp. 1261-1264, 1993.

[32] L. Zheng, F. X. Yang, and H. Qian, "Research on ningxia industrial water resources utilization efficiency based on super-efficient DEA model," Journal of Water Resources and Water Engineering, vol. 150, no. 2, pp. 83-88, 2020.

[33] K. Y. Song and Q. Y. Liu, "research on the investment efficiency evaluation of my country's mining industry in Africa based on super-efficiency DEA model," China Mining, vol. 280, no. 12, pp. 52-58, 2020.

[34] X. X. Lv, J. Q. Wu, and X. H. Zhang, "The development and thinking of scientific and technological innovation activities under the OBE concept," Theoretical Research and Practice of Innovation and Entrepreneurship, vol. 12, pp. 179-180, 2020.

[35] N. M. Liu, X. L. Wang, and H. B. Han, "Research on the spatio-temporal characteristics and driving mechanism of the coordinated development of universities science and technology innovation and high-tech industry innovation," Science of Science and Management of Science and Technology, vol. 36, no. 10, pp. 59-70, 2015.

[36] W. Nasierowski and F. J. Arcelus, "Interrelationships among the elements of national innovation systems: a statistical evaluation," European Journal of Operational Research, vol. 119, no. 2, pp. 235-253, 1999.

[37] A. G. Frank, W. Gerstlberger, and C. A. Paslauski, "The contribution of innovation policy criteria to the development of local renewable energy systems," Energy Policy, vol. 115, pp. 125-140, 2018.

[38] C. Cao and L. Li, "Reforming China's S\&T system," Science, vol. 6145, pp. 460-462, 2013.

[39] T. H. N. D. Andrade, L. R. D. Silva, and L. Gitahy, "New policies for science and technology and the impacts on public research institutes: a case study in Brazil," Brazilian Political Science Review, vol. 7, no. 2, pp. 37-46, 2013.

[40] P. Li and Y. Li, "Research on the contribution of technological infrastructure to technological innovation-an empirical analysis based on panel data in China," Research and Development Management, vol. 25, no. 6, pp. 92-102, 2013.

[41] N. X. Xia, "A comparative study of DF, ADF test and PP test of unit root," Quantitative Economics and Technical Economic Research, vol. 22, no. 9, pp. 129-135, 2005.

[42] J. J. Hu and D. P. Zhang, "Unit root test based on ESTAR model with deterministic trend," Statistics and Decision, vol. 36, no. 7, pp. 19-22, 2020.

[43] Q. Qiu and J. H. Guo, "an empirical analysis of the efficiency of urban science and technology innovation capital based on DEA method," Journal of Chang'an University (Social Science Edition), vol. 22, no. 1, pp. 83-92, 2020.

[44] R. Wang and J. L. Tan, "Exploring the coupling and forecasting of financial development, technological innovation, and economic growth," Technological Forecasting and Social Change, vol. 163, Article ID 120466, 2020. 